\title{
DESOXIDAÇÃO NO FORNO-PANELA FRENTE AOS PARÂMETROS DE AGITAÇÃO DO AÇO LÍQUIDO*
}

lara Takehara Chemale ${ }^{1}$ Gustavo Frassini Pelisser ${ }^{2}$ Wagner Viana Bielefeldt ${ }^{3}$

\section{Resumo}

A fim de obter cada vez mais resultados satisfatórios em escala industrial na produção de aços longos, tem-se avaliado constantemente práticas realizadas no processo para se evitar desperdícios devido a defeitos nos produtos. Baseado neste conceito, este trabalho busca analisar melhores controles para otimização do processo de refino secundário, por meio da análise da eficácia na desoxidação e rendimento de liga frente aos parâmetros de agitação por injeção de gases inertes em um aço baixo carbono produzido na unidade Gerdau Riograndense. Através dos resultados obtidos, pode-se afirmar que rendimento de silício é uma ferramenta adequada para prever o nível de oxidação do aço líquido, a influência do desempenho da escória e que parâmetros de agitação por injeção de gases inertes durante o refino secundário tem influência no desempenho do rendimento de liga e da desoxidação do aço líquido.

Palavras-chave: Desoxidação; Rendimento de liga; Escória; Agitação por injeção de gás inerte.

\section{STUDY OF RELATIONSHIP BETWEEN DEOXIDATION AND INERT GAS STIRRED LADLE SYSTEM IN SECONDARY STEELMAKING}

\section{Abstract}

In order to obtain good results in industrial scale of steel destined to mechanical engineering, the practices in the company's process has been constantly analyzed to avoid wastes due to defects on products. Based on this concept, this paper seeks to analyze the process control to optimize the secondary steelmaking throughout the analysis of effective deoxidation and alloy yield with the inert gas stirred ladle system's parameters of a low carbon steel produced at Gerdau Riograndense steel mill. From the results found, it may be stated that obtaining low oxygen levels in the melt is due to the correct operational practice implemented. Yield alloy is an adequate tool to predict the melt's oxidation levels, the influence on the slag performance and that the inert gas stirred ladle system's parameter during secondary steelmaking influences the performance of yield alloy and deoxidation in the melt.

Keywords: Deoxidation; Yield alloy; Slag; Inert gas stirred ladle system.

Engenheira Metalúrgica, Analista de Qualidade, Tecnologia de Processos e Produtos, Gerdau Aços Brasil - Usina Riograndense, Sapucaia do Sul, RS, Brasil.

2 Engenheiro Metalúrgico, Chefe, Aciaria/Refino Secundário, Gerdau Aços Brasil - Usina Riograndense, Sapucaia do Sul, RS, Brasil.

3 Engenheiro Metalúrgico, Doutor, Professor Adjunto, Departamento de Metalurgia, Universidade Federal do Rio Grande do Sul, Porto Alegre, RS, Brasil. 


\section{INTRODUÇÃO}

Este trabalho apresenta o estudo e a análise dos efeitos da agitação do aço líquido no rendimento de ligas e na desoxidação durante a operação de refino secundário.

O objetivo principal é correlacionar parâmetros de agitação do aço líquido, ou rinsagem ou borbulhamento, no refino secundário, a fim de garantir maior rendimento de liga e desoxidação adequadas para produção de aços longos. A partir de trabalhos já realizados, buscou-se definir aspectos da influência da rinsagem na desoxidação e no rendimento de ligas, além de avaliar faixa de volume e de pressão ideal do gás de rinsagem no refino secundário.

\subsection{Metalurgia de Panela}

\subsubsection{Equilíbrio químico escórias $\mathrm{x}$ aço líquido}

A redução das impurezas do banho de aço, a níveis que minimizem a precipitação de inclusões deletérias, é através de composição adequada para o equilíbrio entre o metal líquido e a escória de panela [1].

Sabe-se que no processo de remoção do oxigênio dissolvido no aço líquido, é necessária a presença de elementos formadores de óxidos estáveis, como $\mathrm{Mn}, \mathrm{Si}$, $\mathrm{Al}, \mathrm{Ca}, \mathrm{Mg}$. Além disso, é necessário minimizar a quantidade de óxidos instáveis na escória como o $\mathrm{FeO}, \mathrm{MnO}$ e $\mathrm{SiO}_{2}$.

\subsubsection{Desoxidação com produtos sólidos ou líquidos}

Como citado por [2], a prática da desoxidação pode ser realizada de duas formas: simples e complexa. Na prática, para obter resultados mais eficientes utiliza-se desoxidação complexa com manganês e silício (semi-killed steels). O motivo de sua maior eficiência é a formação de um composto chamado de silicato de manganês que, além de ser líquido nas temperaturas usuais do aço líquido, resulta em níveis de oxigênio dissolvido mais baixos do que na desoxidação simples.

\subsubsection{Rendimento da adição de ligas ou desoxidantes}

Basicamente, pode-se definir o rendimento de liga pela Equação 1:

$$
\mathrm{R}(\%)=\frac{\text { Elemento no Aço }}{\text { Elemento Adicionado }}
$$

Para obter o rendimento mais próximo de $100 \%$, é necessário que o aço líquido tenha sido desoxidado a um nível tal que a liga adicionada não possua capacidade de reagir e diminuir o teor de oxigênio, que a escória tenha sido prévia e totalmente reduzida e, por fim, a reoxidação pelo ar atmosférico tenha sido evitada.

A desoxidação intensa e a redução da escória nem sempre são possíveis de se obter facilmente, visto que ambas as etapas dependem do teor de oxigênio na chegada do forno-panela.

No caso de aços desoxidados ou acalmados ao Si-Mn, o rendimento do silício tem uma importância fundamental para interpretar o nível de oxidação da corrida de aço. Na Figura 1 pode-se observar que há uma tendência de diminuição dos teores de oxigênio à medida que o rendimento de Si é mais efetivo [3]. 


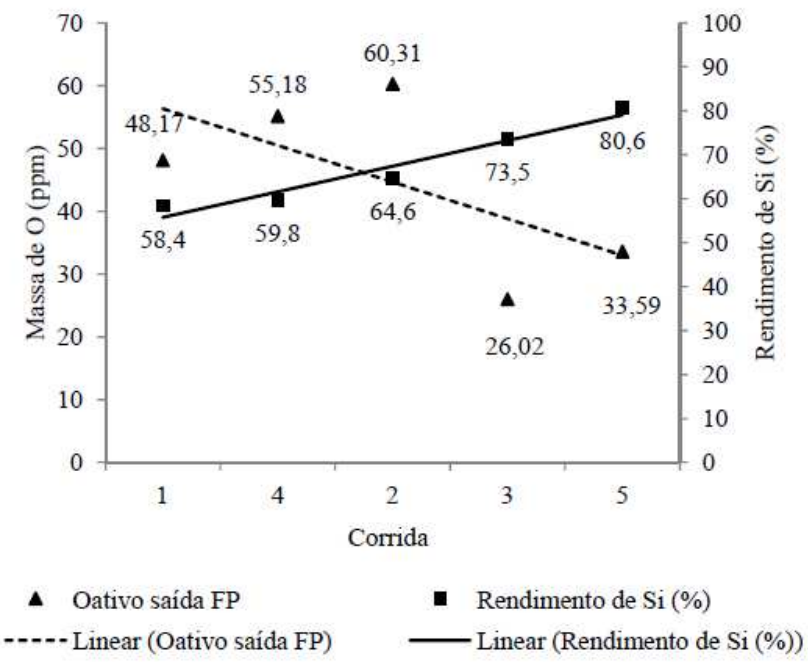

Figura 1 Relação entre $\mathrm{O}_{\text {ativo }}$ e Rendimento de Si após o processo de desoxidação [3]

\subsection{Agitação por Injeção de Gases Inertes}

O processo de agitação - ou rinsagem - do aço líquido é fundamental para a eficiência da operação de refino. Devido a sua flutuabilidade, o gás injetado ascende até a superfície induzindo um fluxo recirculatório turbulento no líquido, o que auxiliza na homogeneização química e térmica além de acelerar a absorção de inclusões não-metálicas pela escória [4]. Além do fluxo do gás injetado, a posição do plugue também é fator importante e pode ser visto em [5-7].

\subsubsection{Formação de bolhas}

Devido à complexidade da dinâmica dos fluidos na prática, inúmeros estudos de simulação entre ar-líquido foram realizados. Sabe-se que a formação de bolhas influencia diretamente no fluxo de gás na pluma, considerada região de duas fases gás e líquido. A relação entre a formação de bolhas e agitação é relacionada através da pressão e volume utilizado durante o processo e pode ser visto na Figura 2.

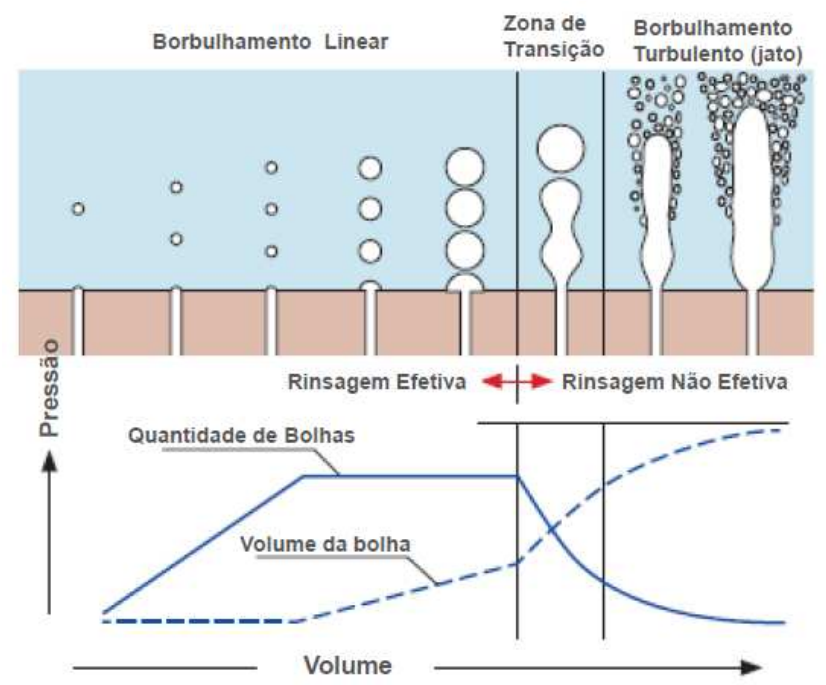

Figura 2 Relação pressão x volume e seu efeito na rinsagem e na formação de bolhas [8]

Observa-se na Figura 2 que há uma faixa de pressão e de volume na rinsagem onde se produz alta quantidade de bolhas com baixo volume. Ou seja, existe uma alta 
área superficial no fluxo de gás injetado, resultando em uma rinsagem efetiva do líquido.

Já para altos valores de pressão e de volume na rinsagem, a quantidade de bolhas diminui e seu volume aumenta. Isto é consequência da coalescência destas bolhas tornando fluxo de gás no líquido turbulento e a rinsagem de baixa eficácia.

Além disso, o posicionamento e quantidade de plugues na panela irá influenciar nos padrões de escoamento da mesma, como mostra a Figura 3.

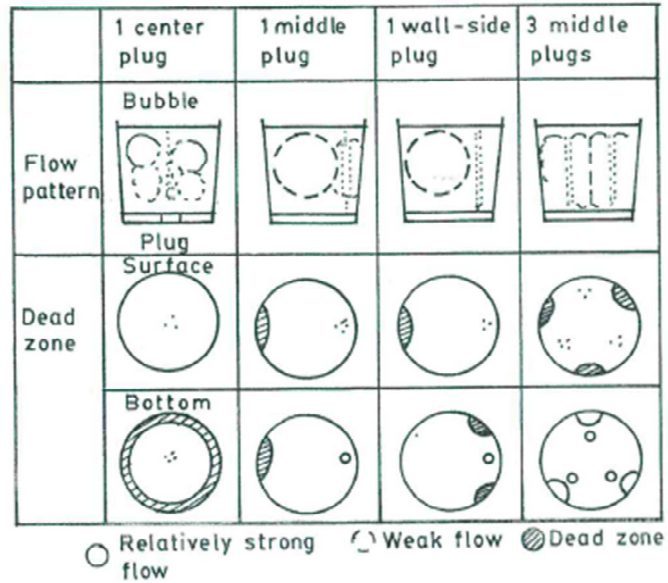

Figura 3 Padrões de escoamento e zonas mortas em panelas para diferentes configurações de plugues [9]

\subsubsection{Influência no processo de desoxidação}

Sabe-se que, durante o refino secundário, a agitação do aço líquido influencia na remoção de produtos da desoxidação. O principal motivo da eficácia da agitação por gás inerte é a adesão das bolhas nas partículas de inclusões, aumentando a flutuação de inclusões menores em direção à superfície [9].

A velocidade com que o oxigênio é removido do aço líquido depende do fluxo do gás de rinsagem [10]. Ou seja, para uma melhor desoxidação do aço líquido, maior deverá ser o fluxo de gás injetado. Porém, é necessário observar que o aumento excessivo da vazão acarreta no aumento de absorção de gás da atmosfera pelo "olho" da pluma [4].

Durante o processo de refino secundário, é importante também observar o tempo de rinsagem das corridas, visto que teor de oxigênio total - consequentemente, dissolvido no aço líquido - apresentam uma relação em função do tempo de rinsagem, conforme mostra a Figura 4.

Observa-se que, após certo tempo de rinsagem, o teor de oxigênio no aço tende a se manter constante. Esta tendência é consequência da ocorrência simultânea da reoxidação do aço. A reoxidação pode ocorrer através de diversos motivos como: contato do aço com a atmosfera, escória oxidada e óxidos de refratários no aço líquido [9]. 


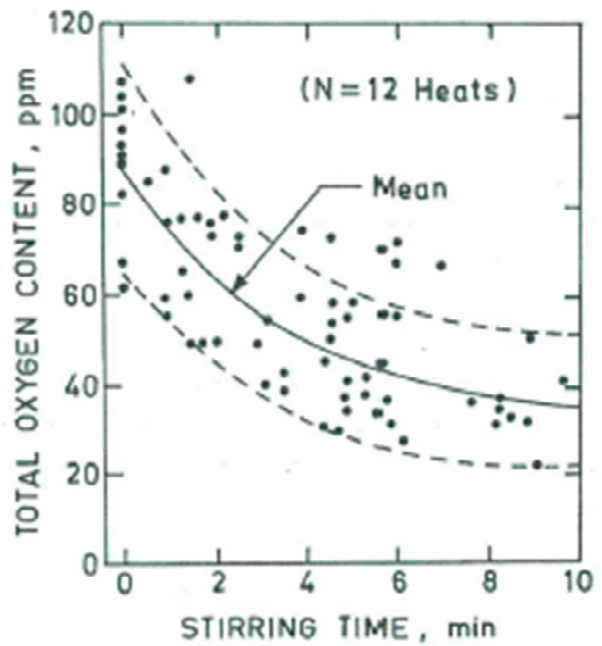

Figura 4 Relação entre massa de oxigênio total (ppm) e o tempo de rinsagem (minutos) [9]

\section{MATERIAIS E MÉTODOS}

\subsection{Materiais}

Para o estudo em questão, foi escolhido um aço baixo carbono cuja composição química objetivada dos elementos desoxidantes durante processo de produção está apresentada na Tabela 1.

Tabela 1 Composição química objetivada do aço analisado.

\begin{tabular}{|c|c|c|c|}
\hline Elemento & \%C & \%Mn & $\%$ Si \\
\hline Comp. Química Objetivada & 0,11 & 0,65 & 0,17 \\
\hline
\end{tabular}

\subsection{Métodos}

\subsubsection{Coleta de dados}

Na Figura 5, tem-se a localização dos pontos de amostragem durante o processo.

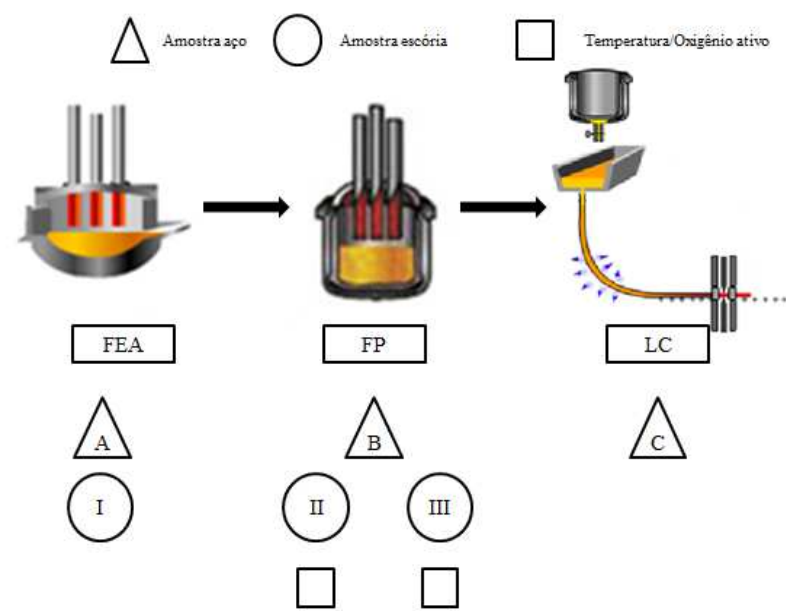

Figura 5 Pontos de amostragem durante processo, onde A/B/C são as amostras de aço e $1 / 1 / / I I$ as amostras de escórias para suas respectivas etapas [11] 
Para a coleta das amostras de aço durante o processo, foi utilizado o amostrador de imersão do fabricante ECIL MetTec. Para a medição de oxigênio ativo no fornopanela, foi utilizado o medidor CELOX Heraeus Electro-Nite.

As amostras de escórias foram retiradas utilizando uma vara tubular que foi imersa na escória onde a mesma ficou aderida.

\subsubsection{Análises químicas}

A análise de composição química do aço foi realizada em cada etapa do processo durante a produção do aço. O equipamento utilizado foi o Espectrômetro de Emissão Óptica, modelo ARL 3460-AES.

A análise para determinação da composição química da escória foi realizada no setor de Tecnologia de Produtos e Processos (TPP) da usina. O equipamento utilizado foi um Espectrômetro de Fluorescência de Raios X, modelo ARL ADVANT'X após preparação prévia das amostras.

\subsubsection{Cálculo de rendimento de \%Si no aço e \%FeO+\%MnO na escória}

Para os cálculos de rendimento de silício da Equação 2 foi levado em consideração o peso vazado das corridas, os teores de silício no aço em cada etapa do processo e as quantidades de silício nas ferroligas adicionadas entre as amostragens.

$$
R_{S i}(\%)=\frac{\left(\left(\left(\% S i_{B}-\% S i_{A}\right) \times M_{\text {aço vazado }}\right) \times 1000\right.}{\left(M_{\text {liga } A} \times 0,15+M_{\text {liga }} \times 0,81+M_{\text {liga }} \times 0,60\right)}
$$

Onde: $\mathrm{R}_{\mathrm{Si}}$ - Rendimento de silício; \%Si $\mathrm{S}_{\mathrm{A}}-$ Teor de silício na amostra do $\mathrm{FEA} ; \% \mathrm{Si}_{\mathrm{B}}-$ Teor de silício na amostra final da corrida (LC); $M_{\text {aço vazado }}$ - Massa de aço líquido vazado na corrida; $M_{\text {liga } A}$ - Massa de liga $A$ adicionada; $M_{\text {liga } B}$ - Massa de liga $B$ adicionada; $M_{\text {liga }} \mathrm{C}-$ Massa de liga $\mathrm{C}$ adicionada.

A relação \%FeO+\%MnO foi obtida através dos resultados de análises químicas da escória para cada amostra.

\section{RESULTADOS E DISCUSSÃO}

Com base nas análises químicas das amostras de aço e de escória combinadas com análise do oxigênio ativo no banho e parâmetros de rinsagem, foi possível obter os resultados descritos. Com o intuito de manter sigilo dos dados da empresa, foram utilizados valores bases para compor os gráficos, porém sempre respeitando delta entre as amostras.

\subsection{Rendimento de Silício}

A relação entre rendimento de silício e oxigênio ativo no banho é demonstrada na Figura 6. 


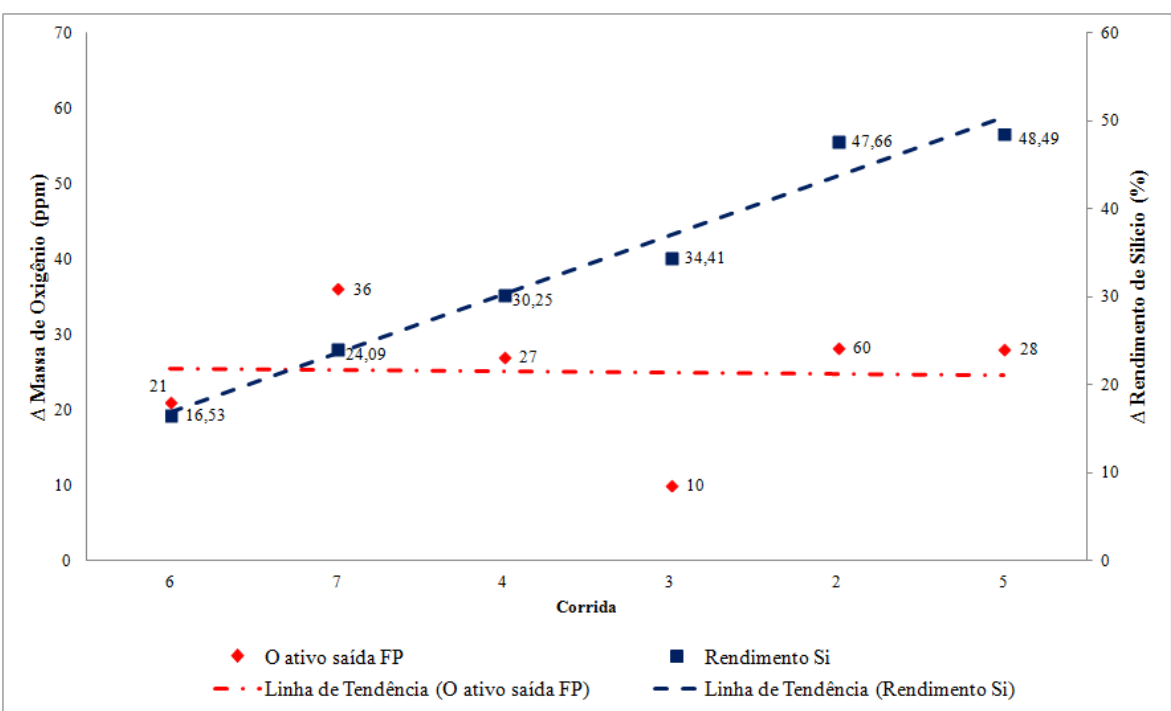

Figura 6 Relação entre $\mathrm{O}_{\text {ativo }}$ e Rendimento de Silício na saída do forno-panela para as corridas analisadas [11]

Observa-se que para uma menor quantidade de oxigênio dissolvido no banho, maior o rendimento de silício. Esta relação também foi comprovada em [3]. Observa-se que a queda no rendimento é mais pronunciada do que o aumento do oxigênio dissolvido no banho. Isso mostra a influência de outros fatores como, por exemplo, a escória, a cinética e a temperatura.

\subsection{Análise das Escórias}

\subsubsection{Composição química da escória}

Na Figura 7, é apresentada a evolução dos óxidos presentes na escória.

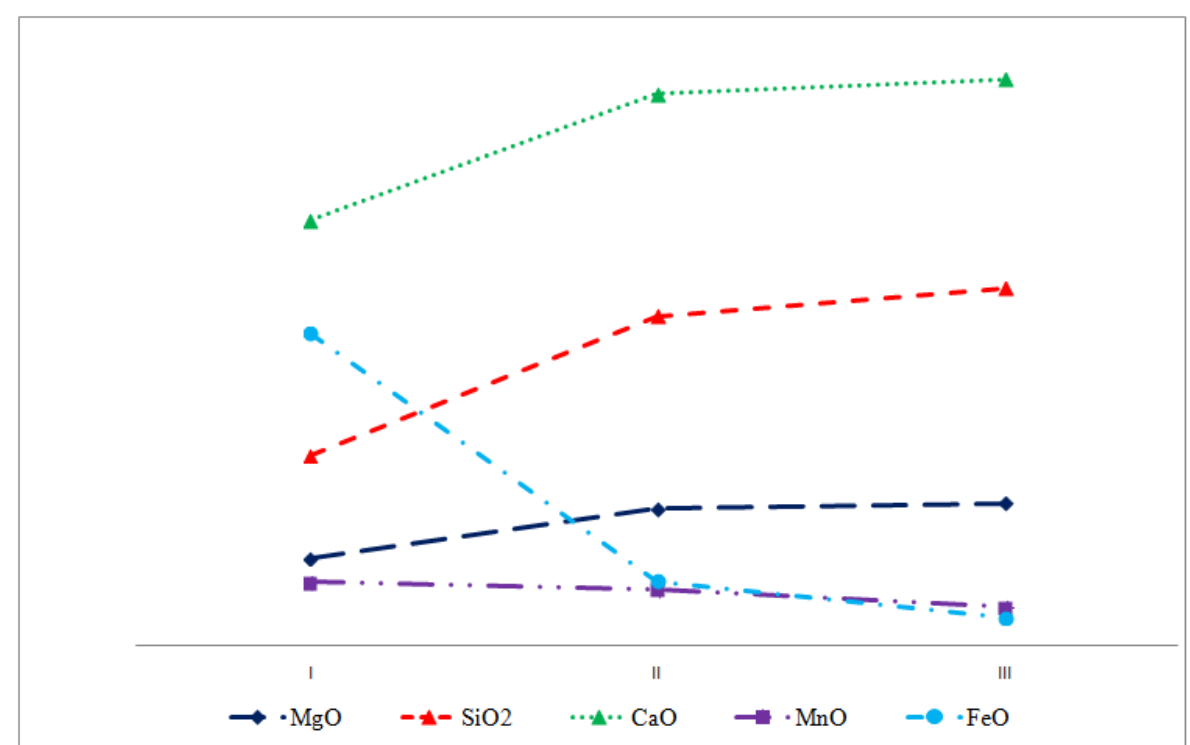

Figura 7 Evolução dos óxidos (\% em massa) presentes na escória durante processo [11]

Observa-se que há uma grande queda do teor de $\mathrm{FeO}$ entre as provas I e II. Isto acontece devido à intensa desoxidação nesta etapa, que ocorre devido à adição de ligas desoxidantes no vazamento do FEA. Esta desoxidação resulta na formação de óxidos, ou seja, gera um aumento no teor de $\mathrm{SiO}_{2}$. Também pode ser observada a diminuição do teor de $\mathrm{MnO}$ que é favorecida pela maior afinidade do oxigênio com o 
silício. Ao realizar a comparação entre as provas II e III, nota-se que os teores dos óxidos de $\mathrm{FeO}$ e de $\mathrm{MnO}$ continuam decrescendo e os teores de $\mathrm{SiO}_{2}$ na escória continuam aumentando. Isto mostra que a desoxidação do aço ainda está ocorrendo.

\subsubsection{Reversão de elementos de ligas}

A partir da análise química da escória, foi possível avaliar a relação das quantidades de \%FeO+\%MnO com a vazão do gás injetado durante a etapa de refino secundário. Esta relação pode ser observada na Figura 8.

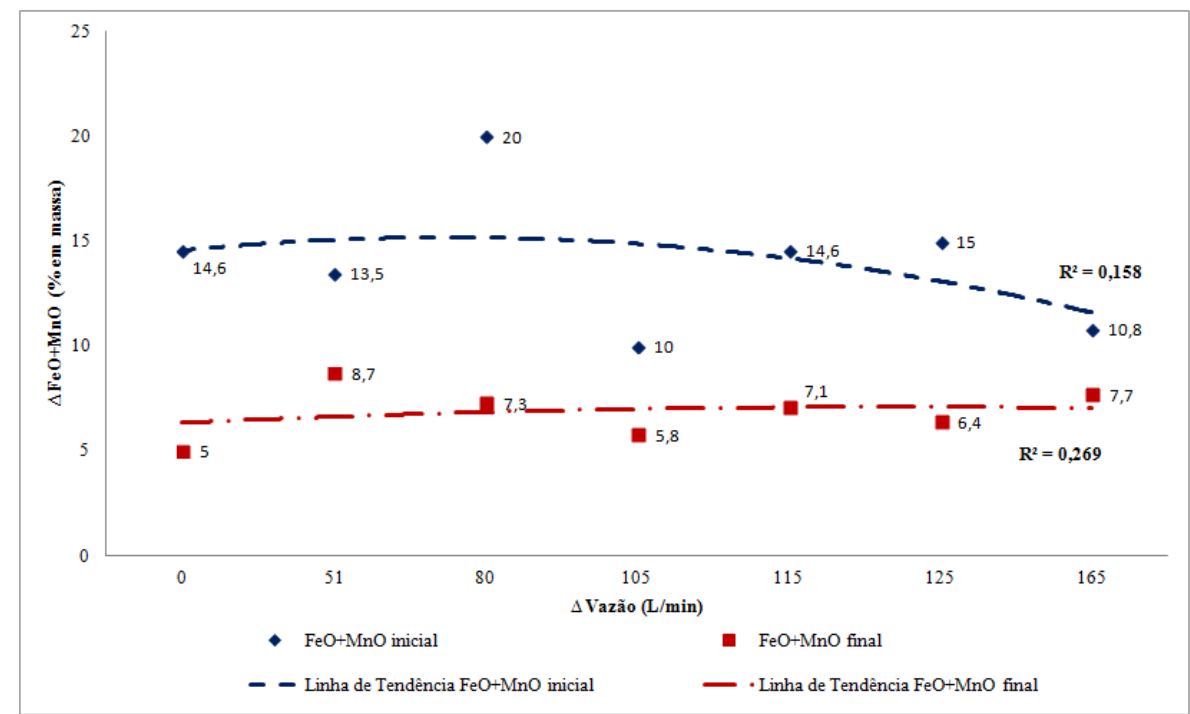

Figura 8 Relação das quantidades de \%FeO+\%MnO inicial e final (\% em massa) com vazão de gás injetado (L/min) para cada corrida [11]

A Figura 8 mostra que a reversão de elementos de ligas, Fe e Mn, da escória para o aço é mais eficaz quando o refino secundário trabalha em vazões menores. Isto se deve ao fato de que, em vazões menores, o escoamento gerado no aço líquido resulta em menor taxa de reoxidação através de contato do aço com atmosfera ou desgaste refratário, como citado em [9].

\subsection{Análise da Injeção de Gases Inertes}

Através das análises químicas das amostras de aço e de escória combinadas com análise do oxigênio ativo no banho e parâmetros de rinsagem, foi possível obter os resultados descritos nos itens 3.3.1 e 3.3.2.

\subsubsection{Relação entre $O_{\text {ativo, }}$ rendimento de $\mathrm{Si}$ e tempo de rinsagem}

A figura 9 mostra a relação do $\mathrm{O}_{\text {ativo }}(\mathrm{em}$ ppm) e do rendimento de $\mathrm{Si}$ (\% em massa) com o tempo de rinsagem para cada corrida analisada (em minutos). 


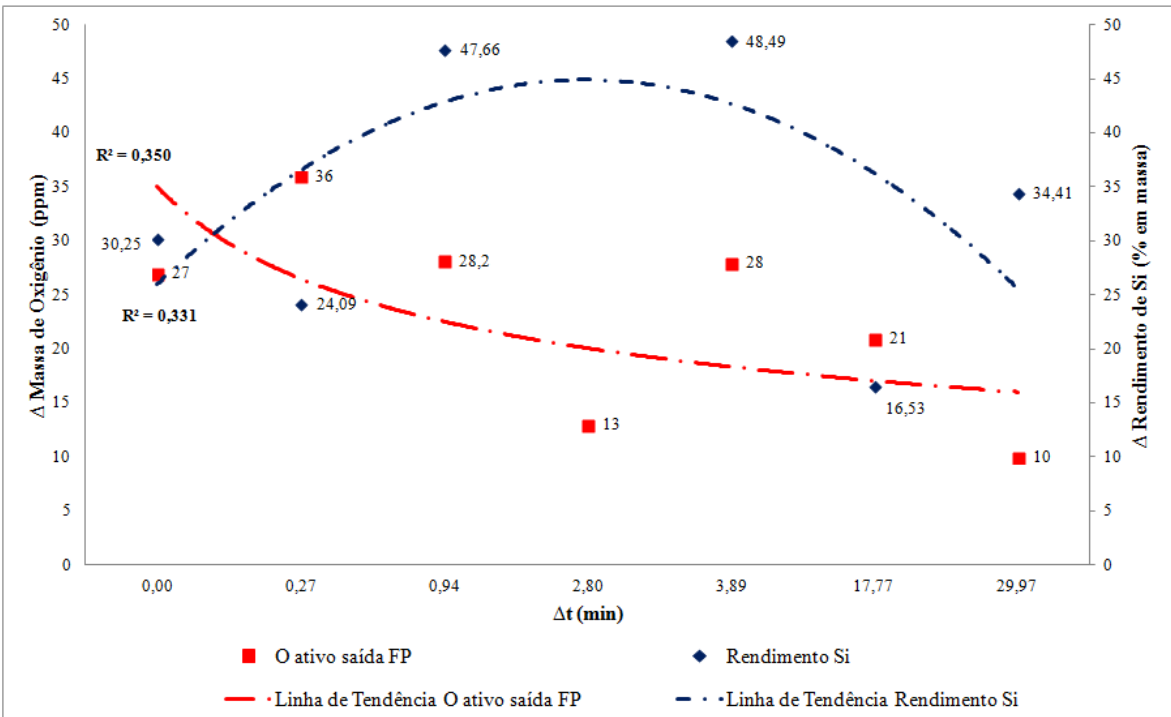

Figura 9 Relação do $\mathrm{O}_{\text {ativo }}(\mathrm{ppm})$ e do rendimento de $\mathrm{Si}$ (\% em massa) com tempo de rinsagem para cada corrida analisada (minutos) [11]

Observa-se na Figura 9 que, para longos tempos de rinsagem, a taxa de desoxidação indica uma tendência a atingir o estado estacionário, mantendo a quantidade de oxigênio ativo no aço constante. Este comportamento é devido ao fato de que, após certo tempo de trabalho no forno-panela, existe uma taxa de reoxidação do banho. Já o rendimento de silício apresenta valor máximo em um tempo de rinsagem intermediário. Ou seja, a partir do momento em que se inicia a reoxidação no aço líquido, o rendimento de silício decai conforme esta taxa se iguala a de desoxidação, conforme mostrado no item 1.2.2.

A partir da Figura 9, observa-se que melhor relação entre rendimento de silício e oxigênio ativo, foi apresentada em tempo intermediário. Esses valores são somente aproximações para as dadas condições, visto que há variação do processo até durante uma mesma campanha. Esta variação de rendimento de liga e desoxidação para certo tempo se deve por diversos fatores, como por exemplo, às zonas mortas presentes na panela e à posição em que as ferroligas e os desoxidantes são adicionados na panela.

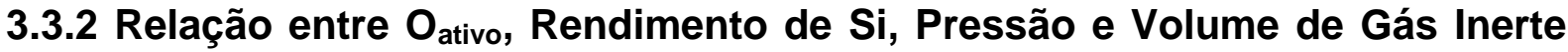 na Panela}

$\mathrm{Na}$ Figura 10 observa-se que a quantidade de oxigênio dissolvido possui valores mais baixos quando combinados pressão intermediária e volume de gás injetado alto. O fato pode ser explicado pela quantidade de bolhas, cujas áreas superficiais influenciam na desoxidação e na flotação de inclusões, conforme descrito no item 1.2.1.

Observa-se que, para o mesmo valor ótimo de oxigênio dissolvido discutido na seção 3.3.1, foi possível definir a faixa de pressão e volume de gás injetado. Isso devido à relação encontrada entre oxigênio ativo e rendimento de silício. $\mathrm{Na}$ Figura 11 é apresentada a relação de rendimento de silício com pressão e volume de gás injetado na panela.

Nota-se que para mesmos valores de pressão e de volume do valor ótimo de oxigênio dissolvido foram observados para valor ótimo de rendimento de silício. 


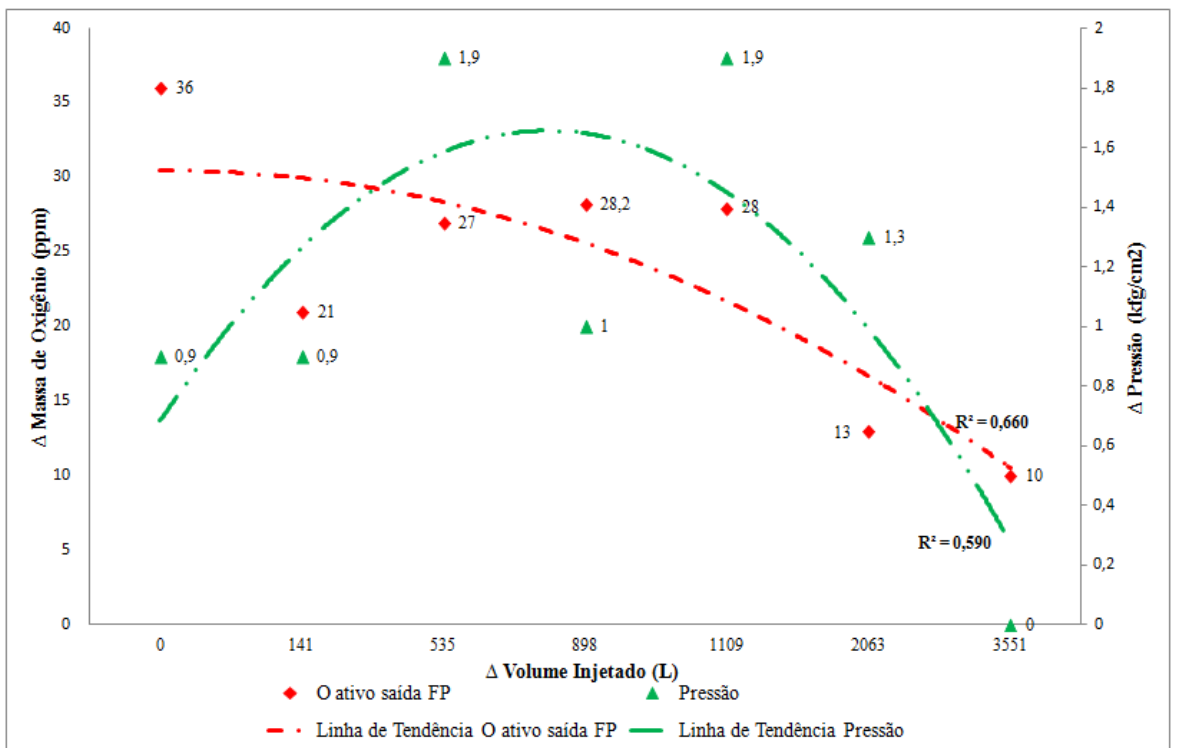

Figura 10 Relação entre o oxigênio ativo na saída do forno-panela (ppm), pressão $\left(\mathrm{kgf} / \mathrm{cm}^{2}\right)$ e volume de gás injetado (L) em cada corrida [11]

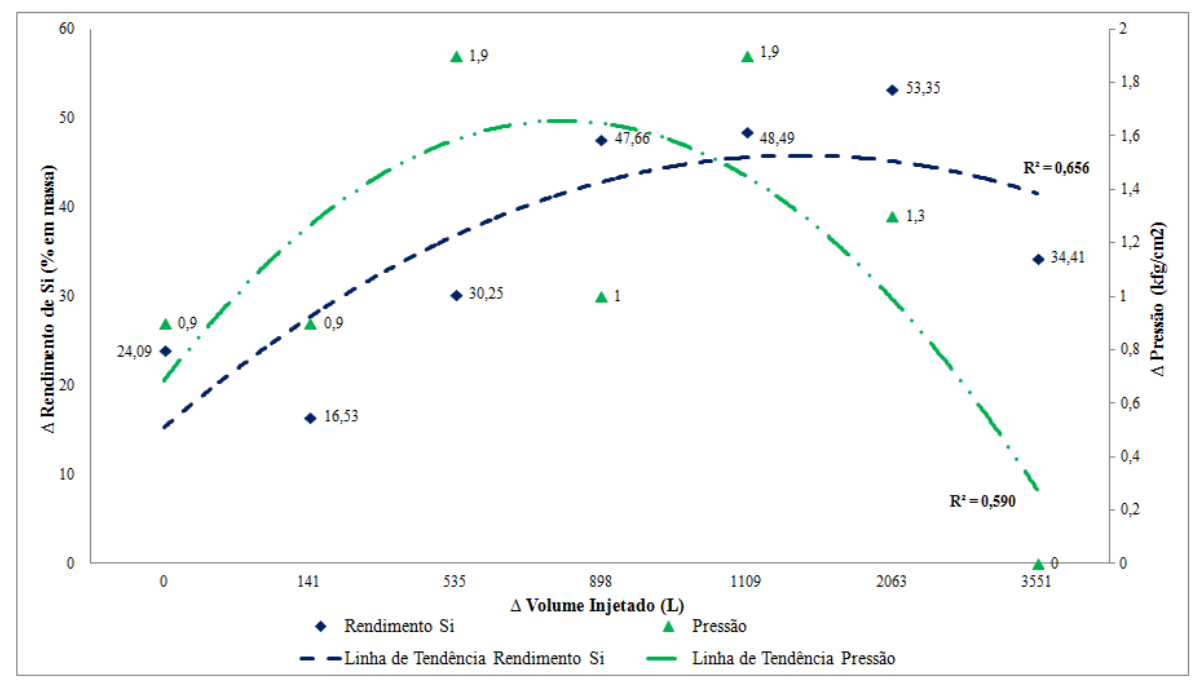

Figura 11 Relação entre o rendimento de silício (\% em massa), pressão $\left(\mathrm{kgf} / \mathrm{cm}^{2}\right)$ e volume de gás injetado (L) em cada corrida [11]

\section{CONCLUSÕES}

Os resultados deste trabalho permitem obter as seguintes conclusões:

1. A relação entre tempo de rinsagem e oxigênio ativo final apresentou comportamento esperado, ou seja, para longos tempos de rinsagem nível de oxigênio tende a estado estacionário;

2. Através da análise de oxigênio ativo junto com tempo de rinsagem, foi possível verificar a faixa ótima de trabalho para um bom rendimento de silício;

3. A reversão de ligas da escória para o aço líquido é favorecida quando são utilizadas vazões menores;

4. Para fins de desoxidação, o melhor resultado ocorre para pressão baixa e volume relativamente alto de gás injetado;

Observação: Esses valores são aplicáveis para panelas com rinsagem de centro, lembrando que a posição do plugue de injeção de gás tem alta influência no processo. 


\section{Agradecimentos}

Agradecemos a Tiago Alliatti Beleza e a Luciana de Carvalho Affonso pela disponibilidade de recursos e apoio no estudo.

Agradecemos também aos consultores Maurício Waineraich Scal e Pedro Bruno Closs Neto pelo conhecimento e incentivo.

\section{REFERÊNCIAS}

1 Gaye HR. The Making, Shaping and Treating of Steel - Inclusion Formation in Steels. Vol. 3, cap.3. Pittsburgh, 2003.

2 Bielefeldt WV. Estudo do Tratamento de Inclusões com Cálcio na Fabricação do Aço SAE 8620. Porto Alegre: PPGEM/UFRGS, 2005.

3 Huppes RM. Estudo de Alternativas para a Identificação e Controle da Desoxidação do Aço no Forno Panela. Porto Alegre: UFRGS; 2014.

4 Mazumdar D, Guthrie RIL. The Physical and Mathematical Modelling of Gas Stirred Ladle System. ISIJ International. 1995: 1-20.

5 Pereira JAM, François MBG, Trindade LB, Vilela ACF. Physical and Numerical Modelling of Steel Process Optimization. 2007: 34-39.

6 Pereira JAM, François MBG, Ribeiro JLD, Vilela ACF. Variation on the Geometric Profile of a Steelmaking Ladle and its Effect on the Mixing. 2006: 34-39.

7 Sicorski FS, Daoud ILA, Pereira JAM, Trindade LB, Vilela ACF. Estudo da Influência do Posicionamento e do Número de Plugs de Injeção de Gás em uma Panela Siderúrgica Através da Ferramenta de CFD. XXXVI Seminário de Fusão, Refino e Solidificação dos Metais - Internacional, 2005: 408-419.

8 RHI. Plug na Metalurgia de Panelas. 2014.

9 Ghosh A. Secondary Steelmaking: Principles and Applications. CRC Press LLC; 2001.

10 Stolte G. Secondary Metallurgy: Fundamentals, Processes, Applications. Alemanha: Woodhead Publishing, 2002.

11 Chemale IT. Estudo de Desoxidação no Forno-panela Frente Aos Parâmetros de Agitação do Aço Líquido. Porto Alegre: UFRGS; 2014. 